\title{
Validation of dengue infection severity score
}

This article was published in the following Dove Press journal:

Risk Management and Healthcare Policy

6 March 2014

Number of times this article has been viewed

\author{
Surangrat Pongpan ${ }^{1,2}$ \\ Jayanton Patumanond ${ }^{3}$ \\ Apichart Wisitwong ${ }^{4}$ \\ Chamaiporn Tawichasri ${ }^{5}$ \\ Sirianong Namwongprom ${ }^{1,6}$ \\ 'Clinical Epidemiology Program, \\ Faculty of Medicine, Chiang Mai \\ University, Chiang Mai, Thailand; \\ ${ }^{2}$ Department of Occupational \\ Medicine, Phrae Hospital, Phrae, \\ Thailand; ${ }^{3}$ Clinical Epidemiology \\ Program, Faculty of Medicine, \\ Thammasat University, Bangkok, \\ Thailand; ${ }^{4}$ Department of Social \\ Medicine, Sawanpracharak Hospital, \\ Nakorn Sawan, Thailand; ${ }^{5}$ Clinical \\ Epidemiology Society at Chiang Mai, \\ Chiang Mai, Thailand; ${ }^{6}$ Department of \\ Radiology, Faculty of Medicine, Chiang \\ Mai University, Chiang Mai, Thailand
}

Correspondence: Sirianong

Namwongprom

Department of Radiology, Faculty

of Medicine, Chiang Mai University,

Chiang Mai 50200, Thailand

Tel +66 53945458

Fax +66 53945476

Email snamwong@med.cmu.ac.th
Objective: To validate a simple scoring system to classify dengue viral infection severity to patients in different settings.

Methods: The developed scoring system derived from 777 patients from three tertiary-care hospitals was applied to 400 patients in the validation data obtained from another three tertiarycare hospitals. Percentage of correct classification, underestimation, and overestimation was compared. The score discriminative performance in the two datasets was compared by analysis of areas under the receiver operating characteristic curves.

Results: Patients in the validation data were different from those in the development data in some aspects. In the validation data, classifying patients into three severity levels (dengue fever, dengue hemorrhagic fever, and dengue shock syndrome) yielded 50.8\% correct prediction (versus $60.7 \%$ in the development data), with clinically acceptable underestimation $(18.6 \%$ versus $25.7 \%$ ) and overestimation (30.8\% versus $13.5 \%$ ). Despite the difference in predictive performances between the validation and the development data, the overall prediction of the scoring system is considered high.

Conclusion: The developed severity score may be applied to classify patients with dengue viral infection into three severity levels with clinically acceptable under- or overestimation. Its impact when used in routine clinical practice should be a topic for further study.

Keywords: dengue hemorrhagic fever, dengue shock syndrome, validation, clinical prediction rule

\section{Introduction}

Dengue viral infection is one of the most challenging tropical diseases internationally. ${ }^{1}$ The infection may be complicated with hypotension ${ }^{2}$ and bleeding abnormality, leading to high mortality. 2,3 The infection also has high economic impact due to high cost of care. ${ }^{4,5}$ Prognostication of disease severity may help clinicians decide which patients should be admitted to hospital, or which patients may safely be treated as outpatients. ${ }^{6}$

A clinical decision rule is a clinical tool that quantifies the individual contributions that various components of the history, physical examination, and basic laboratory results make toward the diagnosis, prognosis, or likely response to treatment in a patient. Clinical decision rules attempt to formally test, simplify, and increase the accuracy of clinicians' diagnostic and prognostic assessments. ${ }^{7}$

A prediction rule for severe dengue infection based on clinical signs and simple laboratory results was successful in predicting dengue hemorrhagic fever (DHF) and dengue shock syndrome (DSS) ${ }^{8}$ Decision tree algorithms,,${ }^{9-12}$ diagnostic decision algorithms, ${ }^{13}$ 
the pediatric logistic organ dysfunction score, ${ }^{14-18}$ and the disseminated intravascular coagulation scoring system ${ }^{19,20}$ were also developed. Other studies were also designed to differentiate dengue fever (DF), ${ }^{9,10}$ types of dengue infection (DF, DHF, or DSS), ${ }^{10,12,13}$ fatal conditions, ${ }^{12}$ development of DHF, ${ }^{11}$ multiple organ dysfunctions, ${ }^{14-16}$ DSS mortality,,${ }^{17,18}$ and disseminated intravascular coagulation. ${ }^{19,20}$

Earlier, we developed a scoring system to help screen patient severity ${ }^{21}$ based on clinical parameters and simple laboratory tests. The present study was conducted to externally validate this scoring system to patients in different settings.

\section{Materials and methods Patients}

Medical files of patients with dengue viral infection aged 1-15 years were retrieved from hospital database, all cases were included in the study. The following International Classification of Diseases (ICD)-10 codes were used: A-90 (DF), A-91 (DHF), and A-910 (DHF with shock).

\section{Definition of dengue severity}

The severity of dengue infection was defined by the following criteria, as in the previous study. ${ }^{21}$

1. Dengue infection - acute or abrupt onset of fever, accompanied by a positive tourniquet test, and white blood count $\leq 5,000 / \mu \mathrm{L}^{22}$

2. DHF - all items of the following: ${ }^{23}$

- Acute or abrupt fever for 2-7 days

- At least one of the following bleeding episodes:

- Positive tourniquet test

- Petechiae, ecchymoses, or purpura

- Bleeding from mucosa, gastrointestinal tract, injection sites, or other location

- Hematemesis or melena

- Platelets $\leq 100,000 / \mu \mathrm{L}$

- At least one of the following plasma leakage evidences:

- Hemoconcentration assessed by an increase in hematocrit $\geq 20 \%$ from previous hematocrit

- Signs of plasma leakage, such as pleural effusion or ascites, or an evidence of hypoalbuminemia

3. DSS - all items for DHF above, accompanied with evidence of circulatory failure, such as: ${ }^{23}$

- Rapid and weak pulse; and

- Pulse pressure $\leq 20 \mathrm{mmHg}$.

Or manifested by:

- Hypotension; and

- Cold body temperature or irritability.
Table I Score assignment scheme for classifying dengue severity

\begin{tabular}{lll}
\hline Clinical characteristic & Criteria & Assigned score \\
\hline Age, years & $>6$ & 1 \\
& $\leq 6$ & 0 \\
Hepatomegaly & Yes & 8.5 \\
Systolic blood pressure, $\mathrm{mmHg}$ & $<90$ & 0 \\
& $\geq 90$ & 2 \\
White cell count, / $\mu \mathrm{L}$ & $>5,000$ & 0 \\
& $\leq 5,000$ & 0 \\
Platelets, / $\mu \mathrm{L}$ & $\leq 50,000$ & 4.5 \\
& $>50,000$ & 0 \\
\hline
\end{tabular}

Notes: Modified from Pongpan S, Wisitwong A, Tawichasri C, Patumanond J. Prognostic indicators for dengue infection severity. Int J Clin Pediatr. 2013;2(I):12-18. ${ }^{8}$ Copyright $(2) 2013$ Surangrat Pongpan et al.

Table 2 Clinical characteristics of dengue patients in the development and the validation data

\begin{tabular}{|c|c|c|c|}
\hline \multirow[t]{2}{*}{ Characteristics } & \multirow{2}{*}{$\begin{array}{l}\text { Development } \\
(n=777)\end{array}$} & \multirow{2}{*}{$\begin{array}{l}\begin{array}{l}\text { Validation } \\
(n=400)\end{array} \\
\text { Mean } \pm \text { SD }\end{array}$} & \multirow[t]{2}{*}{$P$-value* } \\
\hline & & & \\
\hline \multicolumn{4}{|l|}{ Demographic } \\
\hline Male, n (\%) & $376(48.4)$ & $223(55.8)$ & 0.019 \\
\hline Age, years & $9.6 \pm 3.3$ & $10.3 \pm 3.4$ & 0.002 \\
\hline \multicolumn{4}{|c|}{ Mode of presentation, $\mathrm{n}(\%)$} \\
\hline Hepatomegaly & $89(11.5)$ & II (2.8) & $<0.001$ \\
\hline Headache & $408(52.5)$ & $301(75.3)$ & $<0.001$ \\
\hline Myalgia & $126(16.2)$ & $164(4 \mid .0)$ & $<0.001$ \\
\hline Vomiting & $516(66.4)$ & $255(63.8)$ & 0.366 \\
\hline Cough & $246(31.7)$ & $142(35.5)$ & 0.191 \\
\hline Abdominal pain & $401(51.6)$ & $158(39.5)$ & $<0.001$ \\
\hline Rash & $324(41.7)$ & $254(63.5)$ & $<0.001$ \\
\hline Pleural effusion & $54(7.0)$ & $16(4.0)$ & 0.030 \\
\hline Petechiae & $67(8.6)$ & $76(19.0)$ & $<0.001$ \\
\hline Any bleeding episodes & $204(26.3)$ & $121(30.3)$ & 0.149 \\
\hline \multicolumn{4}{|l|}{ Hemodynamic } \\
\hline $\mathrm{SBP}, \mathrm{mmHg}$ & $95.9 \pm 10.0$ & $96.2 \pm 10.0$ & 0.208 \\
\hline $\mathrm{DBP}, \mathrm{mmHg}$ & $58.3 \pm 8.2$ & $58.5 \pm 7.5$ & 0.270 \\
\hline Pulse pressure, $\mathrm{mmHg}$ & $31.0 \pm 8.0$ & $32.6 \pm 20.1$ & $<0.001$ \\
\hline \multicolumn{4}{|l|}{ Hematological } \\
\hline Hematocrit, (\%) & $40.3 \pm 5.0$ & $40.3 \pm 5.2$ & 0.781 \\
\hline Hemoglobin, g/dL & $13.1 \pm 1.6$ & $13.0 \pm 1.7$ & 0.044 \\
\hline \multirow[t]{2}{*}{ White cell count, $/ \mu \mathrm{L}$} & $4,|7| .5 \pm$ & $3,6 \mid 2.4 \pm$ & $<0.001$ \\
\hline & $1,800.3$ & I,202.I & \\
\hline Lymphocytes, (\%) & $42.7 \pm 16.7$ & $40.8 \pm 15.4$ & 0.003 \\
\hline Neutrophils, (\%) & $47.1 \pm 18.5$ & $43.6 \pm 19.0$ & $<0.001$ \\
\hline \multirow[t]{2}{*}{ Platelets, $/ \mu \mathrm{L}$} & $97,569.5 \pm$ & $111,963.2 \pm$ & $<0.001$ \\
\hline & $8,707.0$ & $6,692.2$ & \\
\hline \multicolumn{4}{|l|}{ Biochemical } \\
\hline AST, IU/L & $351.7 \pm 522.7$ & $477.5 \pm 437.0$ & 0.152 \\
\hline$A L T, I U / L$ & $135.8 \pm 324.9$ & $|81.0 \pm 269|$. & 0.048 \\
\hline PT, seconds & $13.7 \pm 6.8$ & $13.3 \pm 2.8$ & 0.796 \\
\hline PTT, seconds & $42.0 \pm 11.5$ & $36.4 \pm 9.1$ & 0.094 \\
\hline \multicolumn{4}{|l|}{ Case management, n (\%) } \\
\hline Inbound referral & $169(21.8)$ & $54(13.5)$ & 0.001 \\
\hline \multicolumn{4}{|l|}{ Discharged } \\
\hline Alive & 775 (99.7) & $400(100.0)$ & 0.551 \\
\hline Outbound referral & $2(0.3)$ & $0(0)$ & \\
\hline Died in hospital & $0(0)$ & $0(0)$ & \\
\hline
\end{tabular}

Note: *P-value from exact probability test or $t$-test or Wilcoxon's rank sum test. Abbreviations: ALT, alanine aminotransferase; AST, aspartate aminotransferase; DBP, diastolic blood pressure; PT, prothrombin time; PTT, partial thromboplastin time; SBP, systolic blood pressure; SD, standard deviation. 
Table 3 Score-derived dengue severity levels in the development and the validation data

\begin{tabular}{|c|c|c|c|}
\hline $\begin{array}{l}\text { Score-classified } \\
\text { severity levels }\end{array}$ & $\begin{array}{l}\text { Development } \\
(n=777)\end{array}$ & $\begin{array}{l}\text { Validation } \\
(n=400)\end{array}$ & $P$-value \\
\hline Mean score $( \pm S D)$ & $5.6 \pm 4.1$ & $4.2 \pm 2.5$ & $<0.001$ \\
\hline Range & $0-18$ & $0-18$ & \\
\hline \multicolumn{4}{|l|}{ Severity levels, n (\%) } \\
\hline DF & $45 \mathrm{I}(58.0)$ & $133(33.3)$ & $<0.00$ I* \\
\hline DHF & $276(35.5)$ & $261(65.3)$ & \\
\hline DSS & $50(6.4)$ & $6(1.5)$ & \\
\hline
\end{tabular}

Note: *P-value from non-parametric test for trend.

Abbreviations: DF, dengue fever; DHF, dengue hemorrhagic fever; DSS, dengue shock syndrome; SD, standard deviation.

\section{Development data}

The original data used to develop the score were obtained from three university-affiliated tertiary-care hospitals in Nakorn Sawan, Kampaeng Phet, and Uttaradit between 2007 and $2010(n=777)$.

\section{Validation data}

The validation data were from similar patients as in the development data in another three university-affiliated tertiary-care hospitals in Phrae, Lamphun, and Chiang Mai during the same period $(\mathrm{n}=400)$.

\section{Data analysis}

The development data and the validation data were compared by exact probability tests or Student's $t$-tests or Wilcoxon's rank sum tests. The severity score was assigned to the patients based on the scoring system proposed from the earlier study, analyzed by multivariable ordinal logistic regression. Assigned item scores were derived by transformation of the coefficients of parameters (Table 1). ${ }^{21}$ The proportions if correct prediction, underestimation, and overestimation in the development and the validation data were compared by areas under the receiver operating characteristic curves
(AuROC). The predictive ability of the scoring system of both datasets was graphically compared by the probability or risk curves.

\section{Results}

Patients in the development and the validation data were similar in the presence of the following symptoms and signs: vomiting, cough, bleeding, systolic blood pressure, diastolic blood pressure, hematocrit, aspartate aminotransferase, prothrombin time, partial thromboplastin time, but were different in gender, age, hepatomegaly, headache, myalgia, abdominal pain, rash, pleural effusion, petechiae, pulse pressure, hemoglobin, white cell count, lymphocytes, neutrophils, platelets, and alanine aminotransferase (Table 2).

The severity score of patients in the development data was higher than in those in the validation data $(5.6 \pm 4.1$ versus $4.2 \pm 2.5, P<0.001)$, and the percentage of DSS was higher $(6.4 \%$ versus $1.5 \%, P<0.001)$ (Table 3 ).

In the validation data, classification of patients into three severity levels (DF, DHF, and DSS) yielded the following results.

- Patients scoring less than 2.5 predicted DF correctly in $21.5 \%$ ( $\mathrm{n}=86$ from 208), with 1-level underestimation in $11 \%(\mathrm{n}=44)$ and 2-level underestimation in $0.8 \%(\mathrm{n}=3)$, a total of $11.8 \%(n=47)$.

- Scores 2.5-11.5 predicted DHF correctly in $28.0 \%$ $(\mathrm{n}=112$ from 157), with an underestimation in $6.8 \%$ $(n=27)$ and an overestimation in 30.5\% $(n=122)$.

- Scores above 11.5 predicted DSS correctly in $1.3 \%(n=5$ from 35$)$, with only 1-level overestimation in $0.3 \%(\mathrm{n}=1)$ (Table 4).

A total correct prediction was obtained in 50.8\% (versus $60.7 \%$ in the development data), with an overall underestimation of $18.6 \%$ (versus $25.7 \%$ ) and an overall overestimation in $30.8 \%$ (versus $13.5 \%$ ).

Table 4 Score-classified severity and criterion-classified dengue severity in the validation data

\begin{tabular}{|c|c|c|c|c|c|c|c|}
\hline \multirow{2}{*}{$\begin{array}{l}\text { Score-classified } \\
\text { severity levels }\end{array}$} & \multirow[t]{2}{*}{ Score range } & \multicolumn{3}{|c|}{ Criterion-classified severity levels } & \multicolumn{3}{|c|}{ Risk estimation validity* } \\
\hline & & $\begin{array}{l}D F \\
n=208\end{array}$ & $\begin{array}{l}\text { DHF } \\
n=157\end{array}$ & $\begin{array}{l}\text { DSS } \\
n=35\end{array}$ & $\begin{array}{l}\text { Over } \\
(\%)\end{array}$ & $\begin{array}{l}\text { Correct } \\
(\%)\end{array}$ & $\begin{array}{l}\text { Under } \\
\text { (\%) }\end{array}$ \\
\hline Mean \pm SD & & $3.3 \pm 1.8$ & $4.4 \pm 2.1$ & $6.5 \pm 3.5$ & & & \\
\hline IQR & & $2.0-4.8$ & $3.8-4.8$ & $4.8-6.8$ & & & \\
\hline \multicolumn{8}{|l|}{ DF } \\
\hline$n=133$ & $<2.5$ & 86 & 44 & 3 & - & 21.5 & 11.8 \\
\hline \multicolumn{8}{|l|}{ DHF } \\
\hline$n=261$ & $2.5-11.5$ & 122 & 112 & 27 & 30.5 & 28.0 & 6.8 \\
\hline \multicolumn{8}{|l|}{ DSS } \\
\hline \multirow[t]{2}{*}{$\mathrm{n}=6$} & $>11.5$ & 0 & I & 5 & 0.3 & 1.3 & - \\
\hline & & & & Total & 30.8 & 50.8 & 18.6 \\
\hline
\end{tabular}

Note: *Percentage of total patients.

Abbreviations: DF, dengue fever; DHF, dengue hemorrhagic fever; DSS, dengue shock syndrome; IQR, interquartile range; SD, standard deviation. 
Table 5 Discriminative performance of the dengue severity score in the development data and the validation data

\begin{tabular}{|c|c|c|c|c|c|}
\hline \multirow[t]{2}{*}{ Prediction/discrimination } & \multicolumn{2}{|c|}{ Development $(n=777)$} & \multicolumn{2}{|c|}{ Validation $(n=400)$} & \multirow[t]{2}{*}{$P$-value } \\
\hline & AuROC (\%) & $95 \% \mathrm{Cl}$ & AuROC (\%) & $95 \% \mathrm{Cl}$ & \\
\hline DHF and DSS versus DF & 74.17 & $72.94-75.37$ & 70.76 & $68.83-72.43$ & 0.003 \\
\hline DSS versus DF and DHF & 88.77 & $87.88-89.64$ & 75.91 & $74.18-77.57$ & $<0.001$ \\
\hline
\end{tabular}

Abbreviations: AuROC, area under receiver operating characteristic curve; $\mathrm{Cl}$, confidence interval; DF, dengue fever; DHF, dengue hemorrhagic fever; DSS, dengue shock syndrome.

The ability of the score to discriminate DF from DHF and DSS was different between the development and the validation data (AuROC $=74.17 \%$ versus $70.76 \%, P=0.003$ ). The ability to discriminate DSS from DF and DHF was also different $($ AuROC $=88.77 \%$ versus $75.91 \%, P<0.001)$, as shown in Table 5 and Figure 1.

\section{Discussion}

The scoring systems for dengue infection in the past were reported to be successful when validated. ${ }^{24} \mathrm{~A}$ simple decision tree using existing data was also successful as a guideline to admit DHF patients into hospitals, reducing unnecessary admission of mild $\mathrm{DF}^{25} \mathrm{~A}$ probability equation and a decision tree for DHF derived in 2004 and internally validated in 2007 was also successful in predicting DHF at first presentation, avoiding unnecessary hospital admission. ${ }^{26}$

The scoring system proposed in the prior study ${ }^{21}$ was less accurate when validated to the new patients. This reduced accuracy may have occurred due to the fact that patients in the validation data were more severe or less severe than the development data, such as seen in this study.

However, from a clinical perspective, this scoring system would be useful in routine practice, as it requires only simple clinical data which can be obtained routinely and is usually available in all levels of patient care centers.

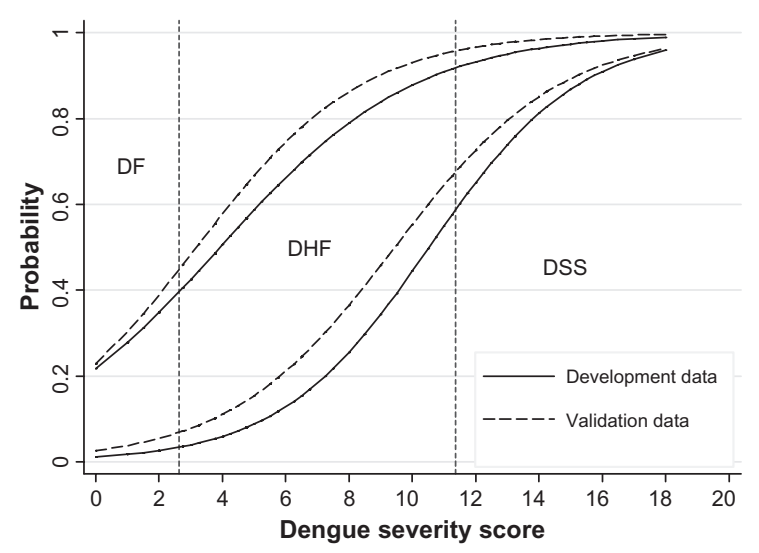

Figure I Score-predicted probability of severity in the development data (solid lines) and the validation data (dashed lines). Vertical dotted lines represent scorederived criteria for classifying patients into DF, DHF, and DSS.

Abbreviations: DF, dengue fever; DHF, dengue hemorrhagic fever; DSS, dengue shock syndrome.
When applied to clinical practice, patients with a low score who are likely to have DF could be treated as outpatients, while those with a higher score who are likely to have DHF could be admitted, and those with the highest score who are likely to have DSS should be admitted for close monitoring, such as in an intensive care unit.

An impact of application of the score into routine clinical practice should be studied further to confirm its usefulness.

\section{Conclusion}

Despite some difference between patients in the validation and in the development data, the scoring system could still discriminate dengue infection severity with clinically acceptable over- or underestimation. The proposed scoring system is likely to be generalized and applied to routine practice in similar patients and settings.

\section{Ethical approvals}

The present study was approved by the Ethics Committee for Research in Patients, the Faculty of Medicine, Chiang Mai University, and the research ethical committees of the six hospitals.

\section{Funding}

The study was partially funded by the Faculty of Medicine, Chiang Mai University.

\section{Acknowledgments}

The authors wish to thank the authorities of the six hospitals for their permission on data collection and wish to thank Chiang Mai University for their financial support.

\section{Disclosure}

The authors report no conflicts of interest in this work.

\section{References}

1. Halstead SB. Dengue. Lancet. 2007;370(10):1644-1652.

2. Chaudhary R, Khetan D, Sinha S, et al. Transfusion support to dengue patients in a hospital based blood transfusion service in north India. Transfus Apher Sci. 2006;35(3):239-244.

3. Chhina DK, Goyal O, Goyal P, Kumar R, Puri S, Chhina RS. Haemorrhagic manifestations of dengue fever and their management in a tertiary care hospital in north India. Indian J Med Res. 2009;129(6): $718-720$. 
4. Kongsin S, Jiamton S, Suaya JA, Vasanawathana S, Sirisuvan P, Shepard DS. Cost of dengue in Thailand. Dengue Bull. 2010;34: 77-88.

5. Suaya JA, Shepard DS, Siqueira JB, et al. Cost of dengue cases in eight countries in the Americas and Asia: a prospective study. Am J Trop Med Hyg. 2009;80(5):846-855.

6. Lee LK, Earnest A, Carrasco LR, et al. Safety and cost savings of reducing adult dengue hospitalization in a tertiary care hospital in Singapore. Trans R Soc Trop Med Hyg. 2013;107:37-42.

7. McGinn TG, Guyatt GH, Wyer PC, et al. Users' guides to the medical literature. XXII: how to use articles about clinical decision rules. JAMA. 2006;284(1):79-84.

8. Pongpan S, Wisitwong A, Tawichasri C, Patumanond J. Prognostic indicators for dengue infection severity. Int J Clin Pediatr. 2013; 2(1):12-18.

9. Lai WP, Chien TW, Lin HJ, Su SB, Chang CH. A screening tool for dengue fever in children. Pediatr Infect Dis J. 2013;32(4): 320-324.

10. Tanner L, Schreiber M, Low JGH, et al. Decision tree algorithms predict the diagnosis and outcome of dengue fever in the early phase of illness. PLoS Negl Trop Dis. 2008;2(3):e196.

11. Brasier AR, Ju H, Garcia J, et al. A three-component biomarker panel for prediction of dengue hemorrhagic fever. Am JTrop Med Hyg. 2012; 86(2):341-348.

12. Thitiprayoonwongse D, Suriyapkol P, Soonthornphisaj N. Data mining of dengue infection using decision tree. Proceeding of the 12 th WSEAS International Conference on Applied Computer Science; 2012 May 11-13; Singapore. Latest Advances in Information Science and Applications. 2012:154-159.

13. Potts JA, Gibbons RV, Rothman AL, et al. Prediction of dengue disease severity among pediatric Thai patients using early clinical laboratory indicators. PLoS Negl Trop Dis. 2010;4(8):e769.

14. Leteurtre S, Duhamel A, Grandbastien B, Lacroix J, Leclerc F. Paediatric logistic organ dysfunction (PELOD) score. Lancet. 2006; 367(9514):897.

15. Leteurtre S, Martinot A, Duhamel A, et al. Validation of the paediatric logistic organ dysfunction (PELOD) score: prospective, observational, multicentre study. Lancet. 2003;362(9379):192-197.

16. Honna L, Triratna S, Triwani, Theodorus. Use of pediatric logistic organ dysfunction (PELOD) in determining prognostic among pediatric intensive care unit patients. Paediatr Indones. 2010;50(6):347-350.
17. Dewi LP, Nurfitri E. Pediatric logistic organ dysfunction score as a predictive tool of dengue shock syndrome outcomes. Paediatr Indones. 2012;52(2):72-77.

18. Iskandar HR, Mulyo D, Agnes P, Suryatin Y. Comparison of pediatric logistic organ dysfunction (PELOD) score and pediatric risk of mortality (PRISM) III as a mortality predictor in patients with dengue shock a mortality predictor in patients with dengue shock syndrome. Pediatrics. 2008;121 Suppl 2:S129.

19. Carlos CC, Oishi K, Cinco MTDD, et al. Comparison of clinical features and hematologic abnormalities between dengue fever and dengue hemorrhagic fever among children in the Philippines. Am J Trop Med Hyg. 2005;73(5):435-440.

20. Oishia K, Mapuae CA, Carlosd CC, et al. Dengue and other febrile illnesses among children in the Philippines. Dengue Bull. 2006;30: 26-34.

21. Pongpan S, Wisitwong A, Tawichasri C, Patumanond J, Namwongprom S. Development of dengue infection severity score. ISRN Pediatr. 2013;2013:845876.

22. Sawasdivorn S, Vibulvattanakit S, Sasavatpakdee M, Iamsirithavorn S Efficacy of clinical diagnosis of dengue fever in paediatric age groups as determined by WHO case definition 1997 in Thailand. Dengue Bull. 2001;25:56-64.

23. World Health Organization [homepage on the Internet]. Dengue hemorrhagic fever: diagnosis, treatment, prevention and control. Geneva: World Health Organization; 1997. Available from: http://www.who. int/csr/resources/publications/dengue/Denguepublication/en. Accessed December 29, 2013.

24. Chang K, Lu P-L, Ko W-C, et al. Dengue fever scoring system: new strategy for the early detection of acute dengue virus infection in Taiwan. J Formos Med Assoc. 2009;108(11):879-885.

25. Lee VJ, Lye DC, Sun Y, Leo YS. Decision tree algorithm in deciding hospitalization for adult patients with dengue haemorrhagic fever in Singapore. Trop Med Int Health. 2009;14(9):1154-1159.

26. Thein TL, Leo Y-S, Lee VJ, Sun Y, Lye DC. Validation of probability equation and decision tree in predicting subsequent dengue hemorrhagic fever in adult dengue inpatients in Singapore. Am J Trop Med Hyg 2011;85(5):942-945.
Risk Management and Healthcare Policy

\section{Publish your work in this journal}

Risk Management and Healthcare Policy is an international, peerreviewed, open access journal focusing on all aspects of public health, policy, and preventative measures to promote good health and improve morbidity and mortality in the population. The journal welcomes submit ted papers covering original research, basic science, clinical \& epidemio-

\section{Dovepress}

logical studies, reviews and evaluations, guidelines, expert opinion and commentary, case reports and extended reports. The manuscript management system is completely online and includes a very quick and fair peerreview system, which is all easy to use. Visit http://www.dovepress.com/ testimonials.php to read real quotes from published authors. 